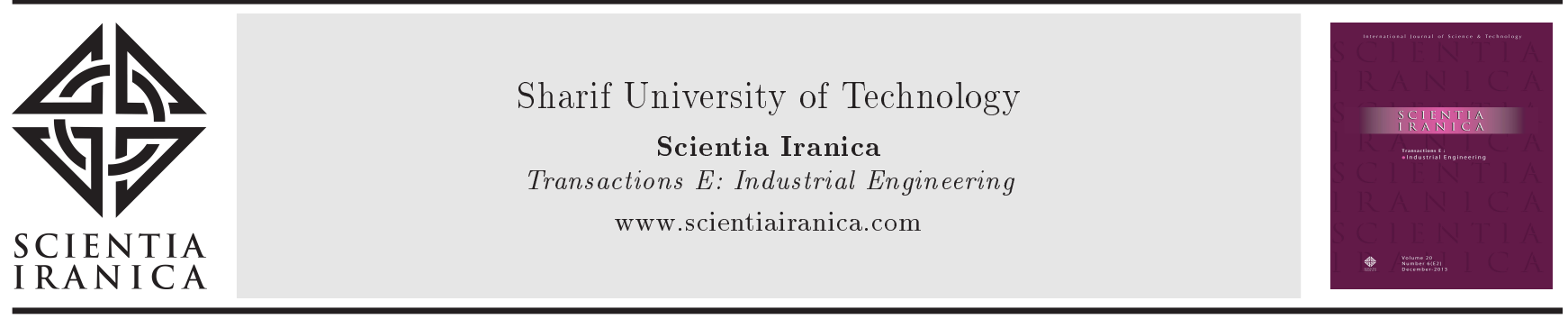

\title{
Optimal replenishment policy with variable deterioration for fixed-lifetime products
}

\author{
B. Kumar Sett ${ }^{a}$, S. Sarkar ${ }^{b}$, B. Sarkar ${ }^{b, *}$ and W. Young Yun ${ }^{\text {c }}$ \\ a. Department of Mathematics, Hooghly Mohsin College, Hooghly, India. \\ b. Department of Industrial \& Management Engineering, Hanyang University, Ansan Gyeonggi-do, 426 791, South Korea. \\ c. Department of Industrial Engineering, Pusan National University, Busan 609-735, Korea.
}

Received 22 October 2014; received in revised form 9 August 2015; accepted 8 December 2015

\section{KEYWORDS}

Ramp-type demand;

Fixed lifetime;

Time-varying

deterioration;

Time-dependent

holding cost;

Shortages.

\begin{abstract}
Although numerous researchers have developed different inventory models for deteriorating items, very few of them have taken the maximum lifetime of a deteriorating item into consideration. This paper illustrates a mathematical model to obtain an optimal replenishment policy for deteriorating items with maximum lifetime, ramp-type demand, and shortages. Both holding cost and deterioration function are linear functions of time, which are treated as constants in most of the deteriorating inventory models. A simple solution procedure is provided to obtain the optimal solutions. Numerical examples along with graphical representations are provided to illustrate the model. Sensitivity analysis of the optimal solution with respect to key parameters of the model has been carried out and the implications are discussed.
\end{abstract}

(C) 2016 Sharif University of Technology. All rights reserved.

\section{Introduction}

It is common nature of human behavior that the customer likes to buy a single item, even though the item is chosen from a large amount of stocks, i.e. the demand rate may go up or down if the onhand inventory level increases or decreases. For this reason, the retailers have to store a large amount of items in their store places. However, certain types of commodities either deteriorate or become obsolete in the course of time. Therefore, they must have an expiry date, i.e. the product will have a maximum lifetime which is time bound; for example, goods like fruits, vegetables, meat, foodstuffs, perfumes, alcohol, gasoline, radioactive substances, photographic films, electronic components, etc., of which deterioration is usually observed. The deteriorated items cannot be used for their original purpose. The loss of inventory

\footnotetext{
*. Corresponding author. Tel.: +82-31-400-5259;

Fax: +82-31-436-8146

E-mail address: bsbiswajitsarkar@gmail.com (B. Sarkar)
}

due to deterioration cannot be ignored. Therefore, it is very essential to know the maximum lifetime of products such that deterioration of products can be controlled. Very few of the existing inventory models in the literature assume the fixed lifetime of products.

Wee [1] considered product's outdate or deterioration as decay, damage, spoilage, evaporation, obsolescence, pilferage, loss of utility, or loss of marginal value of a commodity that results in decreasing usefulness. In this direction, Sana [2] developed optimal sellingprice and lot size with time-varying deterioration and partial backlogging. In the paper, he introduced a new time-dependent deterioration function that followed the maximum lifetime of products. By using the same time-varying deterioration function, Sarkar [3] developed a deteriorating inventory model with tradecredit policy. Sett et al. [4] discussed a two-warehouse inventory model with increasing demand and timevarying deterioration. Sarkar et al. [5] formulated a trade-credit policy with variable deterioration for fixedlifetime products. Wu et al. [6] discussed an optimal credit-period and lot sizing problem for deteriorating 
items with expiration dates under two-level trade credit financing. Sarkar et al. [7] derived retailer's optimal strategy for fixed-lifetime products. Sarkar [8] developed a supply chain coordination with variable backorder, inspections, and discount policy for fixedlifetime products.

Ghare and Schrader [9] were the first authors to consider deterioration in inventory model. Their model is a basic inventory model with constant rate of deterioration. Several authors worked on determining inventory model. Covert and Philip [10] relaxed the assumption of constant deterioration rate by considering a twoparameter Weibull distribution. Further, Philip [11] extended the model by assuming variable deterioration rate. Dave and Patel [12] invented the deteriorating inventory model with increasing linear demand without shortages. Wee [13] formulated an optimal replenishment policy for deteriorating items with a linear pricefunction of demand. Goyal and Giri [14] presented a detailed review of the deteriorating inventory literature. Yang and Wee [15] considered an inventory model with finite replenishment rate and price-sensitive demand for short life cycle and perishable electronic product. Law and Wee [16] developed an integrated productioninventory model for ameliorating and deteriorating items. They used the Discounted Cash Flow (DCF) approach and optimization technique to determine the optimal production and replenishment policy. Chung and Wee [17] discussed a deteriorating inventory model for pricing policy with imperfect production, inspection planning, warranty period, and stock-level-dependent demand. Hsu et al. [18] addressed a deteriorating inventory policy when the retailer invested on the preservation technology to reduce the rate of product deterioration. Sarkar and Sarkar [19] and Sarkar et al. [20] extended different types of inventory model with deterioration. Sarkar [21] considered a productioninventory model for three different types of continuously distributed deterioration functions. Sarkar and Sarkar [22] discussed a control inventory problem with probabilistic deterioration. They solved the model with the help of Euler-Lagrange method. Shah and Cárdenas-Barroán [23] analyzed the retailer's decision for ordering and credit policies when a supplier offered its retailer either a cash discount or a fixed credit period.

On the issue of shortage case, Deb and Chaudhuri [24] were the first authors to incorporate shortage into inventory model. Abad [25] discussed a pricing and lot-sizing problem for deteriorating product by assuming shortages and partial backlogging. Wee et al. [26] discussed an inventory model for ameliorating and deteriorating items with partial backordering under inflation. Without using the calculations for optimality from differential calculus, Cárdenas-Barroán [27] solved an economic production quantity model with basic algebraic procedure. Taleizadeh et al. [28] considered an inventory model to determine the optimal order and shortage quantities for a perishable item when the supplier offered a special sale. Sometimes, managers prefer to use planned backorders to reduce the total system cost. In this direction, Cárdenas-Barroán [29] presented an inventory model with planned backorders to determine the economical production quantity for a single product. Sarkar and Sarkar [30] presented an improved inventory model with partial backlogging, time-varying deterioration, and stock-dependent demand. Most recently, Sakar et al. [31] extended the inventory model with random defective rate, rework process, and variable backorders. Vishkaei et al. [32] used $100 \%$ screening process in an Economic Order Quantity (EOQ) model under shortages and delay-inpayments. Sarkar et al. [33] developed a continuousreview inventory model with backorder price-discount under controllable lead time. Recently, Sarkar et al. [34] discussed a deteriorating inventory model for high-tech products with partial backlogging.

Classical inventory model considers constant demand rate. However, it is observed that the demand rate for electronic goods (e.g., hard disk, RAM, processer, mobile, etc.), new brands of consumer goods coming to the market, and seasonal products (fruits, e.g. mango, orange, etc.) increases linearly at the beginning up to a certain moment as time increases and then stabilizes to a constant rate until the end of the inventory cycle. To represent such type of demand pattern, the term "ramp-type" is used. Mandal and Pal [35] were the first authors to introduce ramptype demand in inventory model. Deterministic and probabilistic demand situations were discussed in that model. Giri et al. [36] developed a single-item singleperiod EOQ model for deteriorating items with a ramptype demand and Weibull distributed deterioration. Manna and Chaudhure [37] developed an EOQ model with ramp-type demand rate, time-dependent deterioration rate, unit production cost, and shortages. They assumed that the time point at which the demand was stabilized occurred before the production stopping time. Skouri et al. [38] discussed an inventory model with general ramp-type demand rate, time-dependent deterioration rate, and partial backlogging. The model was studied under two different replenishment policies: (a) starting with no shortages, and (b) starting with shortages. Skouri et al. [39] extended Manna and Chaudhuri's [39] model by considering that (a) for the model with no shortages, the demand rate was stabilized after the production stopping time, and (b) for the model with shortages, the demand rate was stabilized after the production stopping time or after the time when the inventory level reached zero or after the production restarting time. Sarkar et al. [40] developed an inventory model for imperfect production 
with price- and time-dependent demand. Pal et al. [41] developed an inventory model for deteriorating items with ramp-type demand rate. That model was solved under crisp and fuzzy environment to evaluate the optimum solution in different cases. We summarize our contribution compared with other models in Table 1.

This model considers an inventory system for deteriorating items with ramp-type demand. Every deteriorating item has its expiration date (maximum lifetime), i.e. products may deteriorate with increasing value of time. An interesting relation between the variable increasing time and the fixed lifetime of products is considered in this model. Shortages are allowed, which are fully backlogged. The main purpose of this paper is to develop an optimal replenishment policy which minimizes the total cost per unit time. The necessary and sufficient conditions of the existence and uniqueness of the optimal solutions are provided. Finally, several numerical examples are given to illustrate the theoretical results of this model. Sensitivity analysis of the optimal solution with respect to key parameters and their discursion is given. The rest of the paper is designed as follows: in Section 2, notation and assumptions are given. In Section 3, mathematical model and solution procedure are derived. Numerical experiments and sensitivity analysis are presented to illustrate the model in Section 4. Finally, conclusions are made in Section 5.

\section{Notations and assumptions}

To derive the model, following notations and assumptions are used.

\subsection{Notations}

$Q \quad$ Order quantity per cycle (units);

$\Phi(t) \quad$ Time-dependent deterioration rate;

A Ordering cost per order ( $\$$ /order);

$C_{h} \quad$ Unit inventory holding cost per week (\$/unit/week);

$C_{p} \quad$ Purchasing cost per unit purchase (\$/unit);

$C_{d} \quad$ Deterioration cost $(\$ /$ unit deteriorated);

$C_{s} \quad$ Shortage cost (\$/unit);

$\mu \quad$ Ramp-type demand breaking point parameter (week);

$I(t) \quad$ On-hand inventory level at time $t$;

$t_{1} \quad$ Length of time in which the inventory level falls to zero (week);

$T \quad$ Fixed length of each ordering cycle (week);
$T C_{1}\left(t_{1}\right) \quad$ Total cost for Model I ( $\$ /$ week $)$;

$T C_{2}\left(t_{1}\right) \quad$ Total cost for Model $2(\$ /$ week $)$.

\subsection{Assumptions}

1. The model is considered for a single type of item;

2. The deterioration rate is assumed as $\Phi(t)=\frac{1}{1+\rho-t}$, where $\rho>t$ and $\rho$ is the maximum lifetime of products at which the total on-hand inventory deteriorates. When $t$ increases, $\Phi(t)$ increases and Limt $_{t \rightarrow \rho} \Phi(t) \rightarrow 1$;

3. The demand rate $R(t)$ is assumed to be a ramp-type function of time, i.e.:

$$
R(t)=R_{0}[t-(t-\mu) H(t-\mu)], \quad R_{0}>0,
$$

where $H(t-\mu)$ is the Heaviside's function as follows:

$$
H(t-\mu)=\left\{\begin{array}{lll}
1 & \text { if } \quad t \geq \mu \\
0 & \text { if } \quad t<\mu
\end{array}\right.
$$

4. Holding cost is linear function of time, i.e. $C_{h}(t)=$ $h_{0}+h_{1} t$, where $h_{0}, h_{1}>0$

5. Shortages are allowed and fully backlogged;

6. Lead time is assumed as negligible and the replenishment rate is infinite.

\section{Model formulation}

The model considers an inventory model for deteriorating items with ramp-type demand and stockdependent selling rate. The replenishment at the beginning of the cycle brings the inventory level up to $I_{\max }$. The inventory level decreases during the time interval $\left[0, t_{1}\right]$ due to combined effects of the demand and deterioration, and falls to zero at $t=t_{1}$. Shortages occur during the period $\left(t_{1}, T\right)$, which are fully backlogged.

During the replenishment cycle $[0, T]$, the inventory level, $I(t)$, satisfies the following differential equations:

$$
\begin{aligned}
& \frac{d I(t)}{d t}=-R(t)-\Phi(t) I(t), \quad 0 \leq t \leq t_{1} \\
& \text { with } I(0)=I_{\max }, \\
& \frac{d I(t)}{d t}=-R(t), \quad t_{1} \leq t \leq T, \text { with } I\left(t_{1}\right)=0 .
\end{aligned}
$$

To solve the above differential equations, two cases are considered: (a) $\mu \geq t_{1}$, and (b) $\mu \leq t_{1}$. The fluctuation of the inventory level for the two cases is depicted in Figures 1 and 2, respectively. 
Table 1. Comparison between the contributions of different authors.

\begin{tabular}{|c|c|c|c|c|c|}
\hline Author (s) & $\begin{array}{l}\text { Ramp-type } \\
\text { demand }\end{array}$ & Deterioration & $\begin{array}{l}\text { Maximum } \\
\text { lifetime }\end{array}$ & $\begin{array}{c}\text { Time-dependent } \\
\text { holding cost }\end{array}$ & Shortage \\
\hline Wee [1] & & & $\sqrt{ }$ & $\sqrt{ }$ & $\sqrt{ }$ \\
\hline Sana [2] & & $\sqrt{ }$ & $\sqrt{ }$ & & $\sqrt{ }$ \\
\hline Sarkar [3] & & $\sqrt{ }$ & $\sqrt{ }$ & & \\
\hline $\begin{array}{l}\text { Sett, Sarkar, } \\
\text { and Goswami [4] }\end{array}$ & & $\sqrt{ }$ & $\sqrt{ }$ & & \\
\hline $\begin{array}{l}\text { Sarkar, Saren, } \\
\text { and Cárdenas-Barrón [5] }\end{array}$ & & $\sqrt{ }$ & $\sqrt{ }$ & & \\
\hline $\begin{array}{l}\text { Wu, Ouyang, } \\
\text { Cárdenas-Barrón, and Goyal [6] }\end{array}$ & & $\sqrt{ }$ & $\sqrt{ }$ & & \\
\hline Sarkar, Sarkar, and Yun [7] & & $\sqrt{ }$ & $\sqrt{ }$ & & $\sqrt{ }$ \\
\hline Sarkar [8] & & & $\sqrt{ }$ & & \\
\hline Ghare and Schrader [9] & & $\sqrt{ }$ & & & \\
\hline Covert and Philip [10] & & $\sqrt{ }$ & & & \\
\hline Philip [11] & & $\sqrt{ }$ & & & \\
\hline Dave and Patel [12] & & $\sqrt{ }$ & & & \\
\hline Wee [13] & & $\sqrt{ }$ & & & $\sqrt{ }$ \\
\hline Goyal and Giri [14] & & $\sqrt{ }$ & & & \\
\hline Yang and Wee [15] & & $\sqrt{ }$ & & & \\
\hline Law and Wee [16] & & $\sqrt{ }$ & & & $\sqrt{ }$ \\
\hline Chung and Wee [17] & & $\sqrt{ }$ & & & \\
\hline Hsu, Wee, and Teng [18] & & $\sqrt{ }$ & & & \\
\hline Sarkar and Sarkar [19] & & $\sqrt{ }$ & & & \\
\hline Sarkar, Saren, and Wee [20] & & $\sqrt{ }$ & & & \\
\hline Sarkar [21] & & $\sqrt{ }$ & & & \\
\hline Sarkar and Sarkar [22] & & $\sqrt{ }$ & & & \\
\hline Shah and Cárdenas-Barrón [23] & & $\sqrt{ }$ & & & \\
\hline Deb and Chaudhuri [24] & & & & & $\sqrt{ }$ \\
\hline Abad [25] & & & & & $\sqrt{ }$ \\
\hline Wee, Law, Yu, and Chen [26] & & $\sqrt{ }$ & & & \\
\hline Cárdenas-Barrón [27] & & & & & $\sqrt{ }$ \\
\hline $\begin{array}{l}\text { Taleizadeh, Mohammadi, } \\
\text { Crdenas-Barrn, and Samimi [28] }\end{array}$ & & $\sqrt{ }$ & & & $\sqrt{ }$ \\
\hline Cárdenas-Barrón [29] & & & & & $\sqrt{ }$ \\
\hline Sarkar and Sarkar [30] & & $\sqrt{ }$ & & & $\sqrt{ }$ \\
\hline $\begin{array}{l}\text { Sarkar, Cárdenas-Barrón, } \\
\text { Sarkar, and Singgih [31] }\end{array}$ & & & & & $\sqrt{ }$ \\
\hline Vishkaei, Pasandideh, and Farhangi [32] & & & & & $\sqrt{ }$ \\
\hline Sarkar, Mandal, and Sarkar [33] & & & & & $\sqrt{ }$ \\
\hline Sarkar, Sett, Goswami, and Sarkar [34] & $\sqrt{ }$ & $\sqrt{ }$ & & & $\sqrt{ }$ \\
\hline Mandal and Pal [35] & $\sqrt{ }$ & $\sqrt{ }$ & & & \\
\hline Giri, Jalan, and Chaudhuri [36] & $\sqrt{ }$ & & & & $\sqrt{ }$ \\
\hline Manna and Chaudhuri [37] & $\sqrt{ }$ & $\sqrt{ }$ & & & $\sqrt{ }$ \\
\hline $\begin{array}{l}\text { Skouri, Konstantaras, } \\
\text { Papachristos, and Ganas [38] }\end{array}$ & $\sqrt{ }$ & $\sqrt{ }$ & & & $\sqrt{ }$ \\
\hline $\begin{array}{l}\text { Skouri, Konstantaras, } \\
\text { Manna, and Chaudhuri [39] }\end{array}$ & $\sqrt{ }$ & $\sqrt{ }$ & & & $\sqrt{ }$ \\
\hline Mahapatra, and Samanta [41] & $\sqrt{ }$ & $\sqrt{ }$ & & & \\
\hline This paper & $\sqrt{ }$ & $\sqrt{ }$ & $\sqrt{ }$ & $\sqrt{ }$ & $\sqrt{ }$ \\
\hline
\end{tabular}




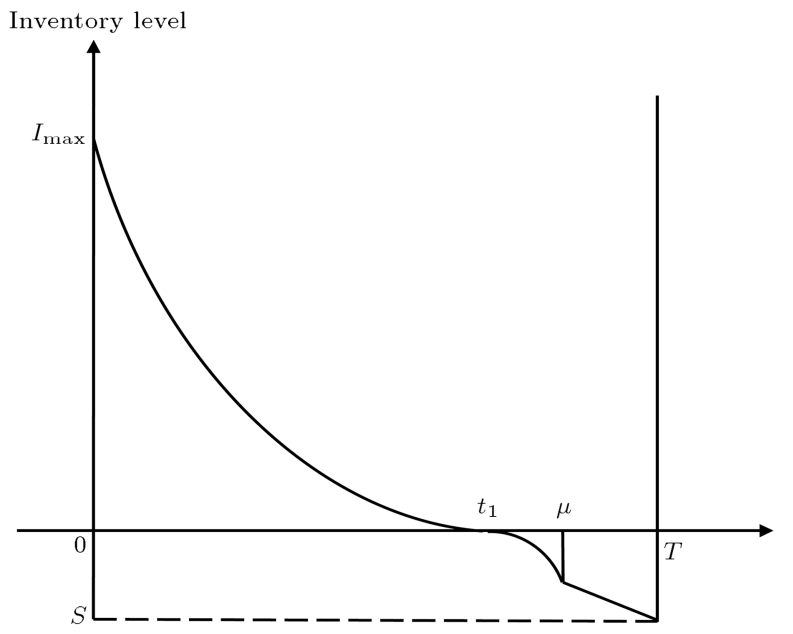

Figure 1. Graphical presentation of the inventory system (Model 1: $t_{1} \leq \mu$ ).

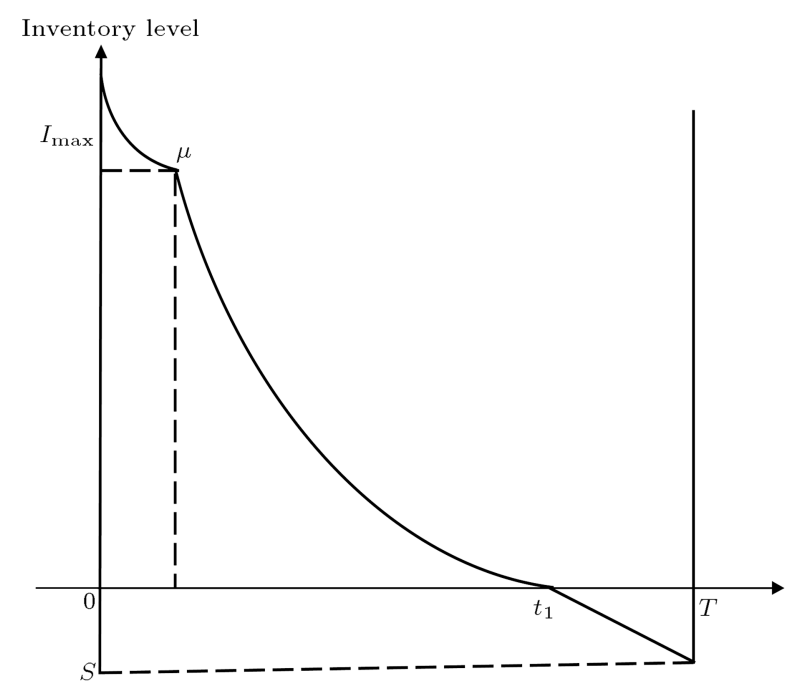

Figure 2. Graphical presentation of the inventory system (Model 2: $t_{1} \geq \mu$ ).

\subsection{Model 1:}

when $\mu \geq t_{1}$, in this case, the demand rate $R(t)$ is:

$$
R(t)= \begin{cases}R_{0} t, & 0 \leq t \leq t_{1} \\ R_{0} t, & t_{1} \leq t \leq \mu \\ R_{0} \mu, & \mu \leq t \leq T\end{cases}
$$

Due to deterioration of items and ramp-type demand rate, the inventory level gradually decreases during the period $\left[0, t_{1}\right]$ and ultimately falls to zero at time $t_{1}$. Therefore, from Eqs. (1) and (2), one has:

$$
\frac{d I(t)}{d t}=-R_{0} t-\Phi(t) I(t) \quad 0 \leq t \leq t_{1}
$$$$
\text { with } I(0)=I_{\max }
$$

$$
\frac{d I(t)}{d t}=-R_{0} t \quad t_{1} \leq t \leq \mu \text { with } I\left(t_{1}\right)=0
$$

$$
\frac{d I(t)}{d t}=-R_{0} \mu \quad \mu \leq t \leq T \text { with }-I(T)=S .
$$

Solution of Eq. (3) is of the form:

$$
\begin{aligned}
I(t)= & R_{0}(1+\rho-t)\left[t+(1+\rho) \ln \left(\frac{1+\rho-t}{1+\rho}\right)\right. \\
& \left.+\frac{I_{\max }}{R_{0}(1+\rho)}\right], \quad 0 \leq t \leq t_{1} .
\end{aligned}
$$

Considering the boundary condition $I\left(t_{1}\right)=0$ and Eq. (6), the maximum inventory level for each cycle is:

$$
I_{\max }=R_{0}(1+\rho)\left[(1+\rho) \ln \left(\frac{1+\rho}{1+\rho-t_{1}}\right)-t_{1}\right] .
$$

After substituting $I_{\max }$ into Eq. (6), it becomes:

$$
\begin{aligned}
I(t)= & R_{0}(1+\rho-t)\left[(1+\rho) \ln \left(\frac{1+\rho-t}{1+\rho-t_{1}}\right)\right. \\
& \left.+\left(t-t_{1}\right)\right], \quad 0 \leq t \leq t_{1} .
\end{aligned}
$$

Solving Eqs. (4) and (5) with the boundary conditions, one has:

$$
\begin{aligned}
& I(t)=\frac{R_{0}}{2}\left(t_{1}^{2}-t^{2}\right), \quad t_{1} \leq t \leq \mu, \\
& I(t)=R_{0} \mu(T-t)-S, \quad \mu \leq t \leq T .
\end{aligned}
$$

Considering the continuity of $I(t)$ at $t=\mu$, it follows from Eqs. (9) and (10) that the maximum amount of demand backlogged per cycle is:

$$
S=R_{0}\left[\mu T-\frac{1}{2}\left(\mu^{2}+t_{1}^{2}\right)\right] .
$$

Substituting the value of $S, \mathrm{Eq}$. (10) becomes:

$$
I(t)=R_{0}\left[\frac{1}{2}\left(\mu^{2}+t_{1}^{2}\right)-\mu t\right], \quad \mu \leq t \leq T .
$$

Thus the order quantity $Q$ is:

$$
\begin{aligned}
Q= & I_{\max }+S=R_{0}\{(1+\rho)[(1+\rho) \\
& \left.\left.\ln \left(\frac{1+\rho}{1+\rho-t_{1}}\right)-t_{1}\right]+\mu T-\frac{1}{2}\left(\mu^{2}+t_{1}^{2}\right)\right\} .
\end{aligned}
$$

Now, the total cost per cycle time consists of the following values:

Ordering cost per cycle $O C=A$. 
Purchase cost per cycle $P C=C_{p} Q$

$$
\begin{gathered}
=C_{p} R_{0}\left\{(1+\rho)\left[(1+\rho) \ln \left(\frac{1+\rho}{1+\rho-t_{1}}\right)-t_{1}\right]\right. \\
\left.+\mu T-\frac{1}{2}\left(\mu^{2}+t_{1}^{2}\right)\right\} .
\end{gathered}
$$

Holding cost per cycle $H C$

$$
\begin{aligned}
& =\int_{0}^{t_{1}} C_{h}(t) I(t) d t=\int_{0}^{t_{1}}\left(h_{0}+h_{1} t\right) I(t) d t \\
& =R_{0}\left[\left\{\frac{(1+\rho)^{3}}{2} \ln \left(\frac{1+\rho}{1+\rho-t_{1}}\right)+\frac{t_{1}}{12}\left[2 t_{1}^{2}\right.\right.\right. \\
& \left.\left.-3 t_{1}(1+\rho)-6(1+\rho)^{2}\right]\right\} h_{0}+\left\{\frac{(1+\rho)^{4}}{6}\right. \\
& \ln \left(\frac{1+\rho}{1+\rho-t_{1}}\right)+\frac{1}{36}\left[3 t_{1}^{4}-6 t_{1}(1+\rho)^{3}\right. \\
& \left.\left.\left.-3 t_{1}^{2}(1+\rho)^{2}-2 t_{1}^{3}(1+\rho)\right]\right\} h_{1}\right] .
\end{aligned}
$$

Deterioration cost per cycle $D C$

$$
\begin{gathered}
=C_{d}\left[I_{\max }-\int_{0}^{t_{1}} R(t) d t\right]=C_{d} R_{0}\{(1+\rho) \\
\left.\left[(1+\rho) \ln \left(\frac{1+\rho}{1+\rho-t_{1}}\right)-t_{1}\right]-\frac{t_{1}^{2}}{2}\right\} .
\end{gathered}
$$

Shortage cost per cycle $S C$

$$
\begin{aligned}
= & C_{s} \int_{t_{1}}^{T}-I(t) d t=C_{s} R_{0} \mu\left(\frac{\mu^{2}}{6}+\frac{t_{1}^{3}}{3 \mu}-\frac{\mu T}{2}\right. \\
& \left.-\frac{T t_{1}^{2}}{2 \mu}+\frac{T^{2}}{2}\right) .
\end{aligned}
$$

Therefore, the average total cost per unit time under the condition $\mu \geq t_{1}$ is:

$$
\begin{aligned}
T C_{1}\left(t_{1}\right)= & \frac{1}{T}[O C+P C+H C+D C+S C] \\
= & \frac{R_{0}}{T}\left[\frac{A}{R_{0}}+h_{0}\left\{\frac{(1+\rho)^{3}}{2} \ln \left(\frac{1+\rho}{1+\rho-t_{1}}\right)\right.\right. \\
& \left.+\frac{t_{1}}{12}\left[2 t_{1}^{2}-3 t_{1}(1+\rho)-6(1+\rho)^{2}\right]\right\} \\
& +\left\{\frac{(1+\rho)^{4}}{6} \ln \left(\frac{1+\rho}{1+\rho-t_{1}}\right)\right. \\
& +\frac{1}{36}\left[3 t_{1}^{4}-6 t_{1}(1+\rho)^{3}-3 t_{1}^{2}(1+\rho)^{2}\right. \\
& \left.\left.-2 t_{1}^{3}(1+\rho)\right]\right\} h_{1}+\left(C_{p}+C_{d}\right)(1+\rho)
\end{aligned}
$$

$$
\begin{aligned}
& {\left[(1+\rho) \ln \left(\frac{1+\rho}{1+\rho-t_{1}}\right)-t_{1}\right]} \\
& +C_{p}\left(\mu T-\frac{\mu^{2}}{2}-\frac{t_{1}^{2}}{2}\right)-\frac{C_{d} t_{1}^{2}}{2} \\
& \left.+C_{s} \mu\left(\frac{\mu^{2}}{6}+\frac{t_{1}^{3}}{3 \mu}-\frac{\mu T}{2}-\frac{T t_{1}^{2}}{2 \mu}+\frac{T^{2}}{2}\right)\right] .
\end{aligned}
$$

\subsection{Model 2:}

when $\mu \leq t_{1}$ In this case, the demand $R(t)$ is:

$$
R(t)=\left\{\begin{array}{l}
R_{0} t, \quad 0 \leq t \leq \mu, \\
R_{0} \mu, \quad=\mu \leq t \leq t_{1}, \\
R_{0} \mu, \quad t_{1} \leq t \leq T
\end{array}\right.
$$

Hence, Eqs. (1) and (2) are reduced to the following equations:

$$
\begin{aligned}
& \frac{d I(t)}{d t}=-\Phi(t) I(t)-R_{0} t, \quad 0 \leq t \leq \mu \\
& \text { with } I_{1}(0)=I_{\max }, \\
& \frac{d I(t)}{d t}=-\Phi(t) I(t)-R_{0} \mu, \quad \mu \leq t \leq t_{1} \\
& \quad \text { with } I_{2}\left(t_{1}\right)=0, \\
& \frac{d I(t)}{d t}=-R_{0} \mu, \quad t_{1} \leq t \leq T, \\
& \text { with } I_{3}\left(t_{1}\right)=0 .
\end{aligned}
$$

Utilizing the boundary conditions, the solutions of Eqs. (14)-(16) are as follows:

$$
\begin{aligned}
I(t)= & R_{0}(1+\rho-t)\left[t+(1+\rho) \ln \left(\frac{1+\rho-t}{1+\rho}\right)\right. \\
& \left.+\frac{I_{\max }}{R_{0}(1+\rho)}\right], \quad 0 \leq t \leq \mu, \\
I(t)= & R_{0} \mu(1+\rho-t) \ln \left(\frac{1+\rho-t}{1+\rho-t_{1}}\right), \\
\mu & \leq t \leq t_{1}, \\
I(t)= & R_{0} \mu\left(t_{1}-t\right), \quad t_{1} \leq t \leq T .
\end{aligned}
$$

Considering the continuity of $I(t)$ at $t=\mu$, the maximum inventory level $I_{\max }$ is obtained from Eqs. (17) and (18) as:

$$
\begin{aligned}
I_{\max }= & R_{0}(1+\rho)\left[\mu\left\{\ln \left(\frac{1+\rho-\mu}{1+\rho-t_{1}}\right)-1\right\}\right. \\
& \left.-(1+\rho) \ln \left(\frac{1+\rho-\mu}{1+\rho}\right)\right] .
\end{aligned}
$$


Using the value of $I_{\max }, \mathrm{Eq} .(17)$ is reduced to:

$$
\begin{aligned}
I(t)= & R_{0}(1+\rho-t)\left[(1+\rho) \ln \left(\frac{1+\rho-t}{1+\rho-\mu}\right)\right. \\
& \left.+\mu \ln \left(\frac{1+\rho-\mu}{1-\rho-t_{1}}\right)+(t-\mu)\right] .
\end{aligned}
$$

Putting $t=T$ in Eq. (19), the maximum amount of demand backlogged per cycle can be obtained as:

$$
S \equiv-I(T)=R_{0} \mu\left(T-t_{1}\right)
$$

Thus, the order quantity $Q$ is:

$$
\begin{aligned}
Q= & I_{\max }+S=R_{0}(1+\rho)\left[\mu\left\{\ln \left(\frac{1+\rho-\mu}{1+\rho-t_{1}}\right)-1\right\}\right. \\
& \left.-(1+\rho) \ln \left(\frac{1+\rho-\mu}{1+\rho}\right)\right]+R_{0} \mu\left(T-t_{1}\right) .
\end{aligned}
$$

Now, the total cost per cycle time consists of the following:

Ordering cost per cycle $O C=A$.

Purchase cost per cycle $P C=C_{p} Q$

$$
\begin{aligned}
= & C_{p}\left\{R _ { 0 } ( 1 + \rho ) \left[\mu\left\{\ln \left(\frac{1+\rho-\mu}{1+\rho-t_{1}}\right)-1\right\}\right.\right. \\
& \left.\left.-(1+\rho) \ln \left(\frac{1+\rho-\mu}{1+\rho}\right)\right]+R_{0} \mu\left(T-t_{1}\right)\right\} .
\end{aligned}
$$

Holding cost per cycle $H C$

$$
\begin{aligned}
= & \int_{0}^{t_{1}} C_{h}(t) I(t) d t=\int_{0}^{\mu}\left(h_{0}+h_{1} t\right) I(t) d t \\
& +\int_{\mu}^{t_{1}}\left(h_{0}+h_{1} t\right) I(t) d t=R_{0}\left\{h _ { 0 } \left[\frac{1}{4}(1+\rho)\right.\right. \\
& (1+\rho-\mu)^{2}-\frac{1}{4}(1+\rho)^{3}+\frac{\mu}{12}\left(3 t_{1}^{2}-\mu^{2}\right. \\
& \left.\left.-6 t_{1}(1+\rho)\right)\right]+\left[h_{1}(1+\rho)+3 h_{0}\right] \\
& \frac{(1+\rho)^{2}}{6}\left[\mu \ln \left(\frac{1+\rho-\mu}{1+\rho-t_{1}}\right)\right. \\
& \left.+(1+\rho) \ln \left(\frac{1+\rho}{1+\rho-\mu}\right)\right]+\frac{h_{1} \mu}{36}\left[\left(3 \mu-6 t_{1}\right)\right. \\
& (1+\rho)^{2}+\left(\mu^{2}-18 \rho-3 t_{1}^{2}\right)(1+\rho) \\
& \left.\left.-6\left(1+\rho^{3}\right)-\mu^{3}+4 t_{1}^{3}\right]\right\} .
\end{aligned}
$$

Deterioration cost per cycle $D C$

$$
\begin{aligned}
& =C_{d}\left[I_{\max }-\int_{0}^{t_{1}} R(t) d t\right] \\
& =C_{d} R_{0}\left\{( 1 + \rho ) \left[\mu\left\{\ln \left(\frac{1+\rho-\mu}{1+\rho-t_{1}}\right)-1\right\}\right.\right. \\
& \left.\left.-(1+\rho) \ln \left(\frac{1+\rho-\mu}{1+\rho}\right)\right]-\left[\frac{\mu^{2}}{2}+\mu\left(t_{1}-\mu\right)\right]\right\} .
\end{aligned}
$$

Shortage cost per cycle $S C$

$$
\begin{aligned}
& =C_{s} \int_{t_{1}}^{T}-I(t) d t \\
& =\frac{C_{s} R_{0} \mu}{2}\left(T-t_{1}\right)^{2} .
\end{aligned}
$$

Therefore, the average total cost per unit time under the condition $\mu \leq t_{1}$ is:

$$
\begin{aligned}
& T C_{2}\left(t_{1}\right)=\frac{1}{T}[O C+P C+H C+D C+S C] \\
& =\frac{R_{0}}{T}\left\{\frac{A}{R_{0}}+h_{0}\left[\frac{1}{4}(1+\rho)(1+\rho-\mu)^{2}\right.\right. \\
& \left.-\frac{1}{4}(1+\rho)^{3}+\frac{\mu}{12}\left[3 t_{1}^{2}-\mu^{2}-6 t_{1}(1+\rho)\right]\right] \\
& +\frac{(1+\rho)^{2}}{6}\left[h_{1}(1+\rho)+3 h_{0}\right][\mu \ln \\
& \left.\left(\frac{1+\rho-\mu}{1+\rho-t_{1}}\right)+(1+\rho) \ln \left(\frac{1+\rho}{1+\rho-\mu}\right)\right] \\
& +\frac{h_{1} \mu}{36}\left[\left(3 \mu-6 t_{1}\right)(1+\rho)^{2}+\left(\mu^{2}-18 \rho-3 t_{1}^{2}\right)\right. \\
& \left.(1+\rho)-6\left(1+\rho^{3}\right)-\mu^{3}+4 t_{1}^{3}\right] \\
& +\left(C_{p}+C_{d}\right)(1+\rho)\left[\mu\left\{\ln \left(\frac{1+\rho-\mu}{1+\rho-t_{1}}\right)-1\right\}\right. \\
& \left.-(1+\rho) \ln \left(\frac{1+\rho-\mu}{1+\rho}\right)\right]+C_{p} \mu\left(T-t_{1}\right) \\
& \left.\left.-C_{d}\left[\frac{\mu^{2}}{2}+\mu\left(t_{1}-\mu\right)\right]\right\}+\frac{C_{s} \mu}{2}\left(T-t_{1}\right)^{2}\right\} \text {. }
\end{aligned}
$$

From the above analysis, one can obtain the total average cost of the system over the interval $[0, T]$ of the form:

$$
T C\left(t_{1}\right)= \begin{cases}T C_{1}\left(t_{1}\right) & \text { if } \mu \geq t_{1} \\ T C_{2}\left(t_{1}\right) & \text { if } \mu \leq t_{1}\end{cases}
$$

It is easy to check if this function is continuous at $\mu$. 


\subsection{Solution procedure}

This section provides the results which can ensure the existence of a unique $t_{1}$ to minimize the total average cost for the model.

Taking first- and second-order derivatives of $T C_{1}\left(t_{1}\right)$ with respect to $t_{1}$, one has:

$$
\frac{d T C_{1}\left(t_{1}\right)}{d t_{1}}=\xi\left(t_{1}\right) f\left(t_{1}\right)
$$

and:

$$
\frac{d^{2} T C_{1}\left(t_{1}\right)}{d t_{1}^{2}}=\xi\left(t_{1}\right) \frac{d f\left(t_{1}\right)}{d t_{1}}+\frac{d \xi\left(t_{1}\right)}{d t_{1}} f\left(t_{1}\right),
$$

where:

$$
\begin{aligned}
f\left(t_{1}\right)= & \frac{(1+\rho)^{2}\left\{3 h_{0}+(1+\rho) h_{1}\right\}}{6\left(1+\rho-t_{1}\right)} \\
& -\frac{1}{6} h_{1}\left\{(1+\rho)\left(1+\rho-t_{1}\right)-2 t_{1}^{2}\right\} \\
& -\frac{1}{2} h_{0}\left(1+\rho-t_{1}\right)+\frac{t_{1}\left(C_{d}+C_{p}\right)}{1+\rho-t_{1}} \\
& -C_{s}\left(T-t_{1}\right) .
\end{aligned}
$$

On the other hand:

$$
f(0)=-C_{s} T<0,
$$

and:

$$
\begin{aligned}
f(T)= & \frac{(1+\rho)}{6}\left(\frac{3 h_{0} T+h_{1} T^{2}}{1+\rho-T}\right) \\
& +\frac{1}{6}\left(3 h_{0} T+2 h_{1} T^{2}\right)+\frac{T\left(C_{d}+C_{p}\right)}{1+\rho-T}>0 .
\end{aligned}
$$

Further:

$$
\begin{aligned}
\frac{d f\left(t_{1}\right)}{d t_{1}}= & C_{s}+\frac{(1+\rho)^{2}\left[3 h_{0}+(1+\rho) h_{1}\right]}{6\left(1+\rho-t_{1}^{2}\right)} \\
& +\frac{(1+\rho)\left(C_{d}+C_{p}\right)}{\left(1+\rho-t_{1}\right)^{2}}+\frac{2}{3} h_{1} t_{1}+\frac{1}{2} h_{0} \\
& -\frac{1}{6} h_{1}(1+\rho)>0 .
\end{aligned}
$$

From Eqs. (27)-(29), one can conclude that $f\left(t_{1}\right)$ is strictly increasing function of $t_{1}$. Therefore, the equation:

$$
f\left(t_{1}\right)=0
$$

has a unique root $t_{1}^{*} \in(0, T)$ for which:

$$
\begin{aligned}
\left.\frac{d^{2} T C_{1}\left(t_{1}\right)}{d t_{1}^{2}}\right|_{t_{1}=t_{1}^{*}} & =\xi\left(t_{1}^{*}\right) \frac{d f\left(t_{1}^{*}\right)}{d t_{1}^{*}}+\frac{d \xi\left(t_{1}^{*}\right)}{d t_{1}^{*}} f\left(t_{1}^{*}\right) \\
& =\xi\left(t_{1}^{*}\right) \frac{d f\left(t_{1}^{*}\right)}{d t_{1}^{*}}>0,
\end{aligned}
$$

so that $t_{1}^{*}$ corresponds to the unconstrained global minimum of $T C\left(t_{1}\right)$.

Taking first- and second-order derivatives of $T C_{2}\left(t_{1}\right)$ with respect to $t_{1}$, one has:

$$
\frac{d T C_{1}\left(t_{1}\right)}{d t_{1}}=\xi(\mu) f\left(t_{1}\right)
$$

and:

$$
\frac{d^{2} T C_{1}\left(t_{1}\right)}{d t_{1}^{2}}=\xi(\mu) \frac{d f\left(t_{1}\right)}{d t_{1}}>0,
$$

where $f\left(t_{1}\right)$ is given by Eq. (26). From the inequality in Eq. (33), following from Eq. (29), one can ensure the strict convexity of $T C_{2}\left(t_{1}\right)$.

Based on the properties of $f\left(t_{1}\right)$, it can be concluded that the first-order derivative of $T C_{2}\left(t_{1}\right)$ with respect to $t_{1}$ vanishes at the point $t_{1}^{*}$, which is a unique solution of $f\left(t_{1}\right)=0$. This $t_{1}^{*}$ corresponds to the unconstrained global minimum of $T C_{2}\left(t_{1}\right)$.

\section{Numerical examples}

This section considers some numerical examples to check the uniqueness of our solution.

Some input parametric values are considered to obtain the optimum results.

\subsection{Example 1}

To derive the optimal solution, two examples are given, which consist of different situations of the ramp-type demand and deteriorated rates. Let us consider the following parametric values: $D_{0}=400, A=\$ 50 /$ order, $h_{0}=\$ 0.1 /$ unit/unit time, $h_{1}=\$ 0.2 /$ unit/unit time, $C_{s}=\$ 1 /$ unit, $C_{p}=\$ 5 /$ unit, $C_{d}=\$ 1.5 /$ unit, $\mu=0.8$, $T=1$ week, and $\rho=5$ months. The optimal value of $t_{1}$ is $t_{1}^{*}=0.4318(<\mu)$ week and the minimum cost per unit of time is $Z_{1}^{*}\left(t_{1}\right)=\$ 1063.33 /$ week (see Figure 3 ).

\subsection{Example 2}

All the parametric values are identical to Example 1, except for $\mu=0.2$. The optimal value of $t_{1}$ is $t_{1}^{*}=$ $0.4318(>\mu)$ week and the minimum cost per unit of time is $Z_{2}^{*}\left(t_{1}\right)=\$ 431.74 /$ week (see Figure 4$)$.

\subsection{Sensitivity analysis}

In this section, the effects of changes in parameters such as $A, C_{s}, C_{p}, C_{d}, h_{1}, h_{2}$, and $L$ on the total cost are studied. The sensitivity analysis is performed by changing each of the parameters by $-50 \%,-25 \%$, $+25 \%$, and $+50 \%$, taking one parameter at a time 


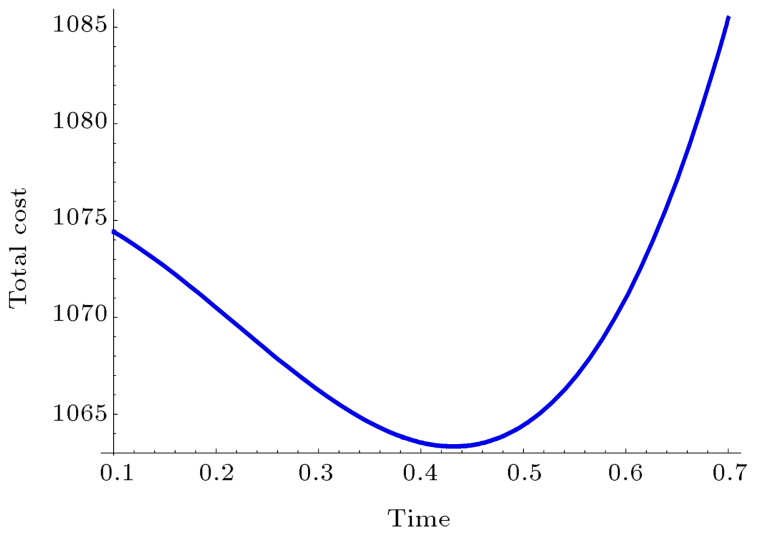

Figure 3. Variation of total cost versus time (Example 1).

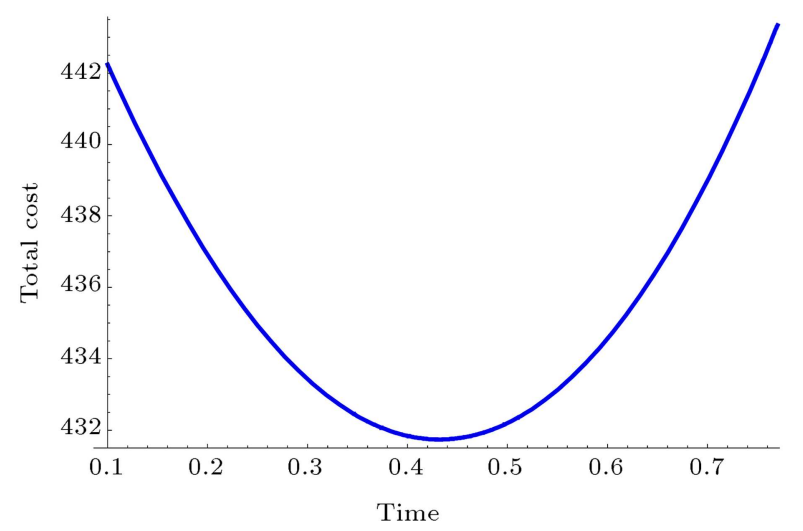

Figure 4. Variation of total cost versus time (Example 2).

while keeping the remaining parameters unchanged. The results are presented in Table 2 .

On the basis of Table 2, the following features are observed:

- Increasing value of ordering cost A increases the material cost, shipping cost, and placing order's cost; as a result, the total relevant cost increases. From Table 2, it is observed that this parameter is a highly a sensitive cost parameter for Model 2 compared to Model 1. For the positive and negative changes in the total cost, it follows symmetrical change;

- Increasing value of shortage cost indicates more shortages in the system, implying increase in total cost. From Table 2, one can notice that this parameter is slightly sensitive to total cost for both models;

- From Table 2, it is noticed that slight change in purchasing cost results in larger change in total cost for both models;

- Increasing values of deterioration cost and holding cost increase the total cost. In both models, these two parameters are slightly sensitive to the total cost;
Table 2. Effects of changes in the parameters on the total costs for Models 1 and 2.

\begin{tabular}{|c|c|c|c|}
\hline Parameters & Changes (in \%) & $Z_{1}\left(t_{1}\right)$ & $Z_{2}\left(t_{2}\right)$ \\
\hline \multirow{4}{*}{ A } & $-50 \%$ & -02.35 & -05.79 \\
\hline & $-25 \%$ & -01.18 & -02.90 \\
\hline & $+25 \%$ & +01.18 & +02.90 \\
\hline & $+50 \%$ & +02.35 & +05.79 \\
\hline \multirow{4}{*}{$C_{s}$} & $-50 \%$ & -02.16 & -01.83 \\
\hline & $-25 \%$ & -01.00 & -00.83 \\
\hline & $+25 \%$ & +00.87 & +00.68 \\
\hline & $+50 \%$ & +01.62 & +01.24 \\
\hline \multirow{4}{*}{$C_{p}$} & $-50 \%$ & -45.75 & -42.57 \\
\hline & $-25 \%$ & -22.83 & -21.24 \\
\hline & $+25 \%$ & +22.76 & +21.16 \\
\hline & $+50 \%$ & +45.49 & +42.28 \\
\hline \multirow{4}{*}{$C_{d}$} & $-50 \%$ & -00.14 & -00.22 \\
\hline & $-25 \%$ & -00.07 & -00.11 \\
\hline & $+25 \%$ & +00.06 & +00.10 \\
\hline & $+50 \%$ & +00.12 & +00.20 \\
\hline \multirow{4}{*}{$h_{1}$} & $-50 \%$ & -00.05 & -00.08 \\
\hline & $-25 \%$ & -00.03 & -00.04 \\
\hline & $+25 \%$ & +00.02 & +00.04 \\
\hline & $+50 \%$ & +00.05 & +00.08 \\
\hline \multirow{4}{*}{$h_{2}$} & $-50 \%$ & -00.02 & -00.02 \\
\hline & $-25 \%$ & -00.01 & -00.01 \\
\hline & $+25 \%$ & +00.01 & +00.01 \\
\hline & $+50 \%$ & +00.02 & +00.02 \\
\hline \multirow{4}{*}{$L$} & $-50 \%$ & +00.56 & +00.98 \\
\hline & $-25 \%$ & +00.27 & +00.44 \\
\hline & $+25 \%$ & -00.24 & -00.37 \\
\hline & $+50 \%$ & -00.46 & -00.67 \\
\hline
\end{tabular}

- Higher maximum lifetime indicates less deterioration, signifying decrease in the total cost.

\section{Conclusions}

In modern marketing environment, a practical problem is to control the deterioration of items. Some products (e.g., fruits, vegetables, pharmaceutical, volatile liquids, etc.) not only deteriorate continuously due to evaporation, obsolescence, spoilage, etc., but also deteriorate with increase in time (i.e., a deteriorating item has a maximum lifetime). In existing literature, very few researchers have considered maximum lifetime of deteriorating items in their model. In this 
regard, the research paper considered an inventory model for products with maximum lifetime, timevarying deterioration rate, and ramp-type demand. A simple solution procedure was given, and existence and uniqueness of the optimal solutions were obtained analytically. This model minimized the associated cost function at the optimal values of the decision variable. Finally, the sensitivity analysis on the optimal solution with respect to key parameters was performed to illustrate the model and some managerial insights were provided. This model used the concept of fixed lifetime of products as a time-varying deterioration rate. The industry managers easily use the suggested policy for their products with fixed lifetime and timevarying deterioration rate. This model can be extended for items having increasing linear demand, price, and advertising-dependent demand or power-demand. This study can be extended further by considering the preservation technology cost for the deteriorating products. One another extension can be considered by assuming multi-item inventory model with inflations.

\section{Acknowledgment}

The authors are thankful to the reviewers for their helpful comments and suggestions to improve the previous version of this paper. This study was financially supported by 2012 Post-Doctoral Development Program, Pusan National University, Korea.

Conflict of interest and support for this research There is no conflict of interest regarding the research area by all authors. The third author has received his financial support from Post-Doctoral Development Program, Pusan National University, Korea, 2012. The rest of the authors have not received any fund for this research.

\section{References}

1. Wee, H.M. "Economic production lot size model for deteriorating items with partialback-ordering", Сomp. Ind. Eng., 24, pp. 449-458 (1993).

2. Sana, S.S. "Optimal selling price and lotsize with timevarying deterioration and partial backlogging", Appl. Math. Comp., 217, pp. 185-194 (2010).

3. Sarkar, B. "An EOQ model with delay in payments and time-varying demand", Math. Comp. Model., 55, pp. 367-377 (2012).

4. Sett, B.K., Sarkar, B. and Goswami, A. "A twowarehouse inventory model with increasing demand and time varying deterioration", Sci. Iran., 19, pp. 1969-1977 (2012).

5. Sarkar, B., Saren, S. and Cárdenas-Barrón, L.E. “An inventory model with trade-credit policy and variable deterioration for fixed lifetime products", Anna. Oper. Res., 229, pp. 677-702 (2015).

6. Wu, J., Ouyang, L.Y., Cárdenas-Barrón, L.E. and Goyal, S.K. "Optimal credit period and lot size for deteriorating items with expiration dates under twolevel trade credit financing", Eur. J. Oper. Res., 237, pp. 898-908 (2014).

7. Sarkar, B., Sarkar, S. and Yun, W.Y. "Retailers optimal strategy for fixed lifetime products", Int. J. Mach. Learn. Cyber., 7, pp. 121-133 (2016).

8. Sarkar, B. "Supply chain coordination with variable backorder, inspections, and discount policy for fixed lifetime products", 2016, Article ID 6318737, 14 pages (2016).

9. Ghare, P.M. and Schrader, G.F. "A model for exponentially decaying inventory system", Int. J. Prod. Res., 21, pp. 449-460 (1963).

10. Covert, R.P. and Philip, G.C. "An EOQ model for items with weibull distribution deterioration", AIIE Trans., 5, pp. 323-326 (1973).

11. Philip, G.C. "A generalized EOQ model for items with Weibull distribution deterioration", AIIE Trans., 6, pp. 159162 (1974).

12. Dave, U. and Patel, L.K. "(T, Si) policy inventory model for deteriorating items with time proportional demand", J. Oper. Res. Soc., 32, pp. 137142 (1981).

13. Wee, H.M. "A replenishment policy for items with a price-dependent demand and a varying rate of deteriorating", Prod. Plan. Cont., 8, pp. 494-499 (1997).

14. Goyal, S.K. and Giri, B.C. "Recent trends in modeling of deteriorating inventory", Eur. J. Oper. Res., 134, pp. 1-16 (2001).

15. Yang, P.C. and Wee, H.M. "A collaborative inventory system with permissible delay in payment for deteriorating items", Math. Comp. Model., 43, pp. 209-221 (2006).

16. Law, S.T and Wee, H.M. "An integrated productioninventory model for amelio-rating and deteriorating items taking account of time discounting", Math. Comp. Model., 43, pp. 673-685 (2006).

17. Chung, C.J. and Wee, H.M. "An integrated production-inventory deteriorating model for pricing policy considering imperfect production, inspection planning and warranty-period and stock-leveldependent demand", Int. J. Syst. Sci., 39, pp. 823-837 (2008).

18. Hsu, P., Wee, H.M. and Teng, H. "Preservation technology investment for deterio-rating inventory", Int. J. Prod. Econ., 124, pp. 388-394 (2010).

19. Sarkar, B. and Sarkar, S. "Variable deterioration and demandan inventory model", Econ. Model., 31, pp. 548-556 (2013).

20. Sarkar, B., Saren, S. and Wee, H.M. "An inventory model with variable demand, component cost and selling price for deteriorating items", Econ. Model., 30, pp. 306-310 (2013). 
21. Sarkar, B. "A production-inventory model with probabilistic deterioration in two-echelon supply chain management", Appl. Math. Model., 37, pp. 3138-3151 (2013).

22. Sarkar, M. and Sarkar, B. "An economic manufacturing quantity model with probabilistic deterioration in a production system", Econ. Model., 31, pp. 245-252 (2013).

23. Shah, N.H. and Cárdenas-Barrón, L.E. "Retailers decision for ordering and credit policies for deteriorating items when a supplier offers order-linked credit period or cash discount", Appl. Math. Comp., 259, pp. 569$578(2015)$.

24. Deb, M. and Chaudhuri, K.S. "A note on the heuristic for replenishment of trended inventories considering shortages", J. Oper. Res. Soc., 38, pp. 459-463 (1987).

25. Abad, P.L. "Optimal pricing and lot sizing under conditions of perishability and partial backordering", Manag. Sci., 42, pp. 1093-1104 (1996).

26. Wee, H.M., Law, S.T., Yu, J. and Chen, H.C. "An inventory model for ameliorating and deteriorating items with partial backordering under inflation", Int. J. Syst. Sci., 39, pp. 801-807 (2008).

27. Cárdenas-Barrón, L.E. "Optimal order size to take advantage of a one-time discount offer with allowed backorders", Appl. Math. Model., 34, pp. 1642-1652 (2010).

28. Taleizadeh, A., Mohammadi, B., Cárdenas-Barrón, L.E. and Samimi, H. "An EOQ model for perishable product with special sale and shortage", Int. J. Prod. Econ., 145, pp. 318-338 (2013).

29. Cárdenas-Barrón, L.E. "Economic production quantity with rework process at a single-stage manufacturing system with planned backorders", Comp. Indu. Eng., 57, pp. 1105-1113 (2009).

30. Sarkar, B. and Sarkar, S. "An improved inventory model with partial backlogging, time-varying deterioration and stock-dependent demand", Econ. Model., 30, pp. 924-932 (2013).

31. Sarkar, B., Cárdenas-Barrón, L.E., Sarkar, M. and Singgih, M.L. "An economic production quantity model with random defective rate, rework process and back-orders for a single stage production system", $J$. Manuf. Syst., 33, pp. 423-435 (2014).

32. Vishkaei, B.M., Pasandideh, S.H.R. and Farhangi, M. " $100 \%$ screening economic order quantity model under shortage and delay in payment", Scien. Iran. E, 21, pp. 2429-2435 (2014).

33. Sarkar, B., Mandal, B. and Sarkar, S. "Quality improvement and backorder price discount under controllable lead time in an inventory model", J. Manuf. Syst., 35, pp. 26-36 (2015).

34. Sarkar, B., Sett, B.K., Goswami, A. and Sarkar, S.A. "Mitigation of high-tech products with probabilistic deterioration and inflation", Amer. J. Indus. Busi. Manag., 5, pp. 73-89 (2015).
35. Mandal, B. and Pal, A.K. "Order level inventory system with ramp type demand rate for deteriorating items", J. Inter. Math., 1, pp. 49-66 (1998).

36. Giri, B.C., Jalan, A.K. and Chaudhuri, K.S. "Economic order quantity model with weibull deterioration distribution, shortage and ramp-type demand", Int. J. Syst. Sci., 34, pp. 237-243 (2003).

37. Manna, S.K. and Chaudhuri, K.S. "An EOQ model with ramp-type demand rate, time-dependent deterioration rate, unit production cost and shortages", Eur. J. Oper. Res., 171, pp. 557-566 (2006).

38. Skouri, K., Konstantaras, I., Papachristos, S. and Ganas, I.S. "Inventory models with ramp-type demand rate, partial backlogging and Weibull deterioration rate", Eur. J. Oper. Res., 192, pp. 79-92 (2009).

39. Skouri, K., Konstantaras, I., Manna, S.K. and Chaudhuri, K.S. "Inventory models with ramp-type demand rate, time-dependent deterioration rate, unit production cost and shortages", Anna. Oper. Res., 191, pp. 73-95 (2011).

40. Sarkar, B., Mandal, P. and Sarkar, S. "An EMQ model with price and time- dependent demand under the effect of reliability and inflation", Appl. Math. Comp., 231, pp. 414-421 (2014).

41. Pal, S., Mahapatra, G.S. and Samanta, G.P. "An EPQ model of ramp-type demand with Weibull deterioration under in environment", Int. J. Prod. Econ., 156, pp. 159-166 (2014).

\section{Biographies}

Bimal Kumar Sett is an Assistant Professor of Mathematics at Hooghly Mohsin College, India. He received his $\mathrm{BSc}$ and $\mathrm{MSc}$ degrees from University of Calcutta. Currently, he is pursuing his $\mathrm{PhD}$ in Applied Mathematics from Vidyasagar University, India. He has published his research papers in Scientia Iranica, American Journal of Industrial and Business Management, International Journal of Applied and Computational Mathematics.

Sumon Sarkar is a Research Assistant in the Department of Industrial \& Management Engineering, Hanyang University, Korea. He received his BSc degree in Mathematics from University of Calcutta, India, and MSc degree in Applied Mathematics from Vidyasagar University, India. He has published several papers in the Journal of Manufacturing System, Applied Mathematics and Computation, Economic Modelling, Journal of Industrial and Management Optimization, International Journal of Machine Learning and Cybernetics, and others.

Biswajit Sarkar is currently an Assistant Professor in the Department of Industrial and Management Engineering of Hanyang University, Korea. He was an 
Assistant Professor of Oceanology and Computer Programming in the Department of Applied Mathematics, Vidyasagar University, India, during 2010 to 2014. He served as an Assistant Professor in the Department of Mathematica at Darjeeling Government College, India, during 2009 to 2010. He received his BSc, MSc, and $\mathrm{PhD}$ degrees from Jadavpur University, India, in 2002, 2004, and 2010, respectively. He was awarded M.Phil in 2008 from Annamalai University, India. His research includes optimization in inventory management, supply chain management, reliability, transportations, and production system. He has published several research papers in international journals of repute, including European Journal of Operational Research, International Journal of Production Economics, Applied Mathematical Modelling, Applied Mathematics and
Computation, Annals of Operation Research, Expert Systems with Applications, Economic Modelling, and others. Presently, he is serving as the Editorial Board Member of several journals. Recently, he became the Editor-in-Chief of the Journal of Engineering and Applied Mathematics, DJ Publications.

Won Young Yun is a Professor in the Department of Industrial Engineering, Pusan National University, Busan, Korea. He received his $\mathrm{ME}$ and $\mathrm{PhD}$ from Korea Advanced Institute of Science and Technology (KAIST) in 1984 and 1988, respectively. His research interests include optimization problems in system reliability, maintenance, warranty, and inland repositioning in which simulation and meta-heuristics are used to find optimal solutions. 